\title{
Utilization of Date palm (Phoenix dactylifera L.) Pruning Residues as Raw Material for MDF Manufacturing
}

\author{
Hossein Hosseinkhani ${ }^{1}$, Markus Euring ${ }^{2}$ \& Alireza Kharazipour ${ }^{2}$ \\ ${ }^{1}$ Wood Science \& Forest Products Research Division, Research Institute of Forests \& Range lands, P.O. Box: \\ 13185-116 Tehran, Iran \\ ${ }^{2}$ Department of Molecular Wood Biotechnology \& Technical Mycology, Büsgen-Institute, Faculty of Forest \\ Science and Forest Ecology, University of Georg-August- Goettingen, Büsgenweg 2, 37077 Goettingen, Germany \\ Correspondence: Alireza Kharazipour, Department of Molecular Wood Biotechnology \& Technical Mycology, \\ Büsgen-Institute, Faculty of Forest Science and Forest Ecology, University of Georg-August- Goettingen, \\ Büsgenweg 2, 37077 Goettingen, Germany. E-mail: akharaz@gwdg.de
}

Received: September 19, 2014 Accepted: October 21, 2014 Online Published: December 7, 2014

doi:10.5539/jmsr.v4n1p46

URL: http://dx.doi.org/10.5539/jmsr.v4n1p46

\begin{abstract}
Fiber of Date Palm (Phoenix dactylifera L) pruning residues are a potential source for the production Medium Density Fiberboard (MDF). Dry process was employed to produce MDF in pilot plant scale using three categories of manufacturing parameters, i.e., two resin types, two resin content levels and three pressing times. Due to the availability of the materials in the pilot plant, Date palm and also soft wood fibers (Pinus silvestries L.) as reference were used for the MDF production under the same parameters.

Three boards were manufactured with combination of variables, and samples of all boards were tested according to the methods of European (EU) standard. As main technological properties modulus of rupture (MOR), modulus of elasticity (MOE), internal bond strength (IB), and formaldehyde emission were determined. Also, samples of each board were tested for thickness swelling and water absorption after soaking in water for $2 \mathrm{~h}$ and $24 \mathrm{~h}$ respectively. In addition all the mechanical and physical properties of boards were derived from analysis procedures.

The results of this study showed that boards made of Date Palm pruning residues fibers featured better properties than the MDF property requirements which was recommended by ASTM and EN standards particularly inspect of mechanical properties. In addition, the formaldehyde (HCHO) emission of the panels featured that almost all the boards met the minimum requirement according to EN 120 especially for the panel bonded with MUF resin. Therefore, Date palm could be proposed as an alternative material for the manufacture of MDF.
\end{abstract}

Keywords: Date Palm (Phoenix dactylifera L), Pinus silvestries L., pruning residues, MDF, MOR, MOE, IB, formaldehyde emission

\section{Introduction}

MDF can be made from a wide variety of lignocellulosic materials and an important implication of this is the use of recycled materials and non-wood fibers in its manufacture. Many softwoods, hardwoods and even bamboo (Wang, 1991), rice husks and waste paper (Dube, 1995) have been used successfully in the manufacture of MDF, although the type of wood used in its manufacture strongly influence board properties (Myers, 1983). The decline in raw materials deleteriously affects the MDF sector, as well as others. Consequently, the forestry industry seeks new substitute materials (Roffael \& Dix, 1992). Since agricultural and horticultural residues are plentiful, widespread, and easily accessible (Hosseinkhani et al., 2008) researchers are now studying their use as raw material substitutes. Several studies have examined the feasibility of substituting wood in composites (Hosseinkhani, 2013), Bagasse and logging residues of Eucaliptus (Hosseinkhani et al., 2000), sunflower stalks (Kargarfard et al., 2009), and kiwi pruning (Kargarfard et al., 2009), were studies to produce composite panels.

Date Palm (Phoenix dactylifera L.) is Monocot and it has been widely cultivated for its fruits. It is estimated that there are more than 105 million Date Palms covering an area of 800.000 ha around the world (Djerbi, 1995). Date Palms should be pruned and the quantity and quality of the fruit are directly dependent on the leaves. After old leaves begin to die, turn brown and hang lifelessly alongside the trunk of the palm, dead leaves should be cut, and 
removed when they no longer have value. It is therefore, considered useful, at present juncture, to carry out a research on the possibility of using pruning residues of Date Palm tree in MDF manufacture.

\subsection{Distribution and Ecology of Date Palm}

The date palm requires high temperatures and low humidity to set fruit and ripen to maturity. The date palm grows best in temperatures above $-7^{\circ} \mathrm{C}$. However, they can survive into the mid to lower teens for short periods of time. For pollen germination, a temperature of $35^{\circ} \mathrm{C}$ is needed. As with most palms, research has shown that warm to hot night temperatures also promotes faster growth. Areas with warmer night temperature promote faster palm growth than those that cool off at night. The best growing conditions for palms are deep soils, preferably sand 3 to 5 feet deep, and a good supply of either sub-surface or irrigation water. Date palms grow naturally between 15 and 35 degrees north latitude in the Sahara, and in the southern fringe of the Near East. The date palm is found throughout the Middle East, and in the northern, eastern, and southern areas of Africa. They are also found in North America, Southern Europe, and Central and South America (FAO, 2002). It is estimated that there are more than 105 million date palms covering an area of 800.000 ha.

\subsection{Availability of Residues}

Date Palm economic life is at about 25-30 years and they should be pruned (Figure 1). The quantity and quality of the fruit are directly dependent on the leaves.

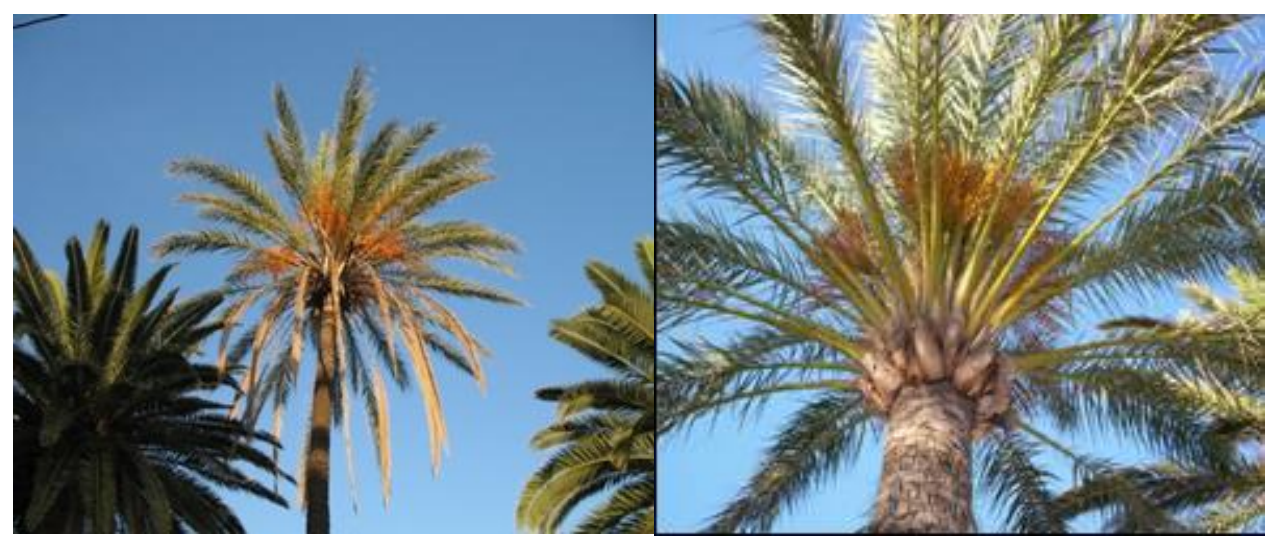

A. Date Palm tree before pruning

B. A Date Palm tree after pruning

Figure 1. A Date Palm tree in site sampling - Iran

Latibari et al. (1996) noted that each tree produces $34 \mathrm{Kg}$. residues annually which $52 \%$ of them are leaves and moreover it can be strongly said that at least $10 \mathrm{Kg}$. residues are produced by each tree yearly (Tables 1 and 2 ).

Table 1. Estimated residues of each tree

\begin{tabular}{ccc}
\hline Parts & $\begin{array}{c}\text { Amount } \\
(\mathrm{Kg} .)\end{array}$ & $\begin{array}{c}\text { Residues of Each tree } \\
(\%)\end{array}$ \\
\hline Leave & 18 & 52.94 \\
Bundle & 6 & 17.56 \\
Bundle arm & 7 & 20.59 \\
Sheath & 3 & 8.82 \\
Total & 34 & 100 \\
\hline
\end{tabular}

Ref. Latibari et al. (1996). 
Table 2. Estimated residues of each leave

\begin{tabular}{cccc}
\hline Parts & $\begin{array}{c}\text { Weight } \\
(\text { Kg. })\end{array}$ & $\begin{array}{c}\text { Residues of branch } \\
(\%)\end{array}$ & Total residues of tree (\%) \\
\hline Midrib & 5.4 & 30 & 15.88 \\
Rachis & 7.8 & 43.33 & 22.94 \\
Leaflet & 4.8 & 26.67 & 14.12 \\
Total & 18 & 100 & 53 \\
\hline
\end{tabular}

Ref. Latibari et al. (1996).

\section{Materials and Methods}

\subsection{Materials}

Fiber material made from Date palm (Phoenix dactylifera. L) was used as raw material for the production of MDF in pilot scale. Urea-Formaldehyde resin (UF), containing 67\% solid content, with the mark of "KAURITEC407 liquid" from the BASF Company, Ludwigshafen, Germany and Melamine Urea-Formaldehyde resin (MUF), containing 70\% solid content, with the mark of "KAURAMIN LEIM627 liquid" from the same Company were used for board production.

Also, paraffin agent was used as hydrophobic and it has a trademark of "Hydro-WAX 730" from the SASOL-Company, Hamburg.

Moreover it is known that a wide range of resin technologies, including many hardeners have been developed, to offer the best possible solution for the different process conditions employed by a variety of customers so, in this study Ammonium chloride were used as hardener.

\subsection{Methods}

\subsubsection{Fiber Production}

Raw materials (Date palm pruning resides) were collected from Iran, Khuzestan Province. They chipped and then sent to the University of Gottingen-Germany for further process, were carried to Klauditz-Wilhelm-Institut Brunswick (WKI) and were weighted to obtain information for later refining process. Thermo-mechanical processes (TMP) for digestion process in which at a temperature of $135^{\circ} \mathrm{C}$, a pressure of 3.2 bar and a digestion time up 5 minutes were used. The production of fiber was done with a continuous process in which wood particles were softened by pre-heating under pressure prior to a pressurized refining stage. After preparation of fibers, they run with very high speed through the blow line for drying. This leads the fibers reduce their moisture content from $120 \%$ to approximately $8 \%$.

\subsubsection{Board Manufacturing in Pilot Plant}

In this study, Date palm (Phoenix dactylifera L) fibers and Pinus sylvestris fibers as reference were used in the production of MDF Panels under the same parameters. At the beginning, the humidity of the fiber materials was measured by using moisture analyzer in which at least seven measurements were carried out, thus, the average value was taken. The percentage of moisture content in the fibers is necessary to indentify because the amount of glue and the fibers itself which is needed in the later mat forming were depend largely on it. These measurements were done twice, one was made prior to gluing process, and the other one was after gluing is completely done.

In the production process, fiber materials were passed through a blender immediately to make the fibers fully separated from each other and then through the tube dryer to get dry and finally reaching the fiber bunker for temporary storing. Until this step, first measurement of moisture was carried out. The value obtained was used to determine how much glue is needed for the next gluing process. Gluing time was calculated based on the fibers passed throughput the entire process of the plant and it was defined of about $60 \mathrm{~kg}$ in 45 minutes. From the bunker, fibers then were passed strewing head to scatter the fibers to have more contact area to attack glue. After that, they were moved down to the belt conveyor and deposited in the mat forming part. Starting from this part, the dried fibers back to conveyer belt and gluing process was made in the blender by spraying the glue onto the entire fibers surface. The amount of glue sprayed was manually adjusted in control panel by measuring its volume per minute or ( $\mathrm{kg}$ glue lutro/minute) adapted to the amount of fiber passing through the blender in $(\mathrm{kg} / \mathrm{h})$. This process was running continuously in which fibers and glue were blended together in the same time until finish. After that, the glued fibers were passed again through the tube dryer to get dry. The burner was responsible to produce heat with 
the help of a ventilator, which produce vacuum and pressure to move the fibers material. It was set to allow furnish to be dried down to $10 \%-12 \%$ of its humidity. After passing the tube dryer, the fibers were transferred to the cyclone to remove the heat. For the second time the moisture content was taken. Glued fibers then was conveyed to the bunker, screwing head, and collected under pre-press area. The purpose of pre-pressing is to reduce the volume of the mattress to be placed in the press. Without using the pre-press facility that available in the MDF pilot line, therefore, mats were hand formed in a frame without fiber orientation. Prior to hot-press, mats was covered by two sheets of metal in bottom and upper sides and at the right and left sides of the mat were placed with two steel sticks to fix the target thickness of the later panels when hot-press is applied. Also, protective paper sheets were placed between the fiber mat and two sheets of metal to avoid adhesion between them during hot pressing. After hot-pressed, the covers including sticks were removed and the panels were labeled and stored overnight before they were being grinded and trimmed.

\subsubsection{Variables Factors}

In this study, variables factors for making boards from both Date palm (Phoenix dactylifera L) fibers and Pinus sylvestris fibers as reference were as follows:

\section{- $\quad$ Resin type 2 levels ( UF and MUF resins)}

- $\quad$ Resin contents 2 levels (10 and 12 percents based on oven dried wood weight)

- $\quad$ Pressing Times 3 levels (1, 2 and 3 min)

Other factors such as type of board, board density, board thickness, Paraffin content, pressing pressure, pressing temperature, and etc were invariable factors. The glue compositions consist of $2 \%$ hydrophobic in UF resin and $1 \%$ hardener (ammonium chloride, solid content $33 \%$ ). The targeted density was $750 \mathrm{~kg} / \mathrm{m}^{3}$ with having the size of about $60 \mathrm{~cm} \times 45 \mathrm{~cm}$ and the thickness of $9 \mathrm{~mm}$. Pressing times applied to all panels were 1, 2 and $3 \mathrm{~min}$. The temperature of the two platens was set at $180^{\circ} \mathrm{C}$.

\subsubsection{Testing Methods}

Prior to mechanical and physical property testing, the specimens were conditioned at 65 percent relative humidity and $20^{\circ} \mathrm{C}$. Three-point static bending MOR and modulus of elasticity (MOE) and internal bond strength tests were performed in conformity with EU standards using a Zwick/Roell-testing machine having type of T1 FR010TH A50. Thickness swelling and water absorption measurements were also made by immersing specimens in water in a horizontal position for 24 hours at ambient temperature. Mechanical and physical properties were tested using specimens cut from the selected experimental panels (Figure 2). All panels were weighed and measured and the SG was calculated. The panels were selected on the basis of the target SG $(0.75 \pm 0.01)$ and target thickness $(9$ $\mathrm{mm}$.). This method of panel selection allowed us to narrow the variability in SG between individual experimental panels.

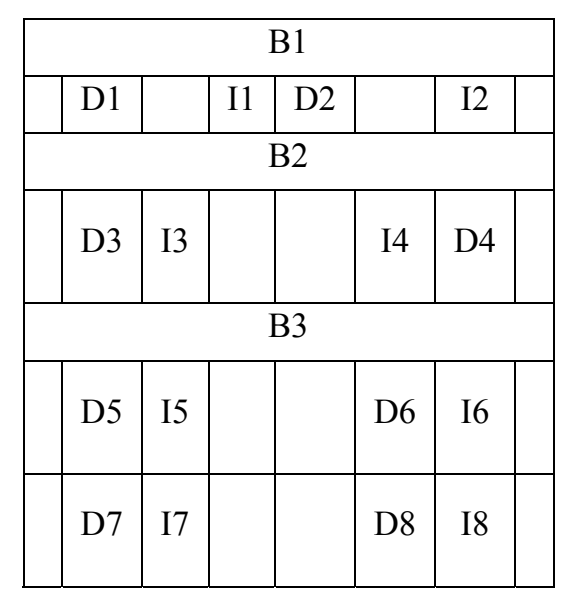

Figure 2. Cutting Pattern for both Physical and Mechanical properties specimens

B1-B3 Bending Strength (44* $5 \mathrm{~cm}$ ).

D1-D8 Density and thickness swelling of Samples $(5 * 5 \mathrm{~cm})$.

I1-I8 Internal Bond strength of Samples $(5 * 5 \mathrm{~cm})$.

Samples (100gr.) for free formaldehyde test were prepared from B1 sample. 
The property tests for Specific gravity (SG), density profile, Thickness swelling (TS), Water absorption (WA), Modulus of rupture (MOR), Modulus of elasticity (MOE), Internal bond (IB) and formaldehyde emission were conducted in accordance with the EU standard (Table 3).

Table 3. Test and test specimen sizes and number

\begin{tabular}{lccl}
\hline Test & specimen & specimen per panel & References \\
\hline Bending strength & $5 * 23(\mathrm{~cm})$ & 3 & EN 310 \\
Internal bond & $5 * 5(\mathrm{~cm})$ & 8 & EN 319 \\
Density & $5 * 5(\mathrm{~cm})$ & 8 & EN 323 \\
Moisture content & $5 * 5(\mathrm{~cm})$ & 8 & EN 322 \\
Thickness swelling & $5 * 5(\mathrm{~cm})$ & 8 & EN 317 \\
Formaldehyde emission & $100 \mathrm{~g}$ & 1 & EN 622-1 \\
\hline
\end{tabular}

\subsection{Statistical Analysis}

The data were evaluated using an analysis of variance procedure for a completely randomized design. Duncan test with $\alpha=0.01$ was performed to permit separation of means. SAS was used for all statistical analyses (SAS, 1996). Results were considered significant at $P<0.01$.

\section{Results and Discussion}

\subsection{Specific Gravity}

The target specific gravity (SG) of boards is $0.75 \mathrm{~g} / \mathrm{cm}^{3}$, while an average specific gravity is $0.74 \mathrm{~g} / \mathrm{cm}^{3}$ on average moisture content level of $8.64 \%$. This result suggests that the average board specific gravity is slightly lower than the target one (board specific gravity). It may provide an explanation as a spring back phenomenon of the board after pressing, since the internal board strength cannot resist the internal stress due to excess steam pressure which could not release from the mat during hot pressing. Consequently, the board thickness increases and the density of the boards decrease after pressing or during conditioning. These findings are confirmed by the thickness deviation of board. The results showed that the nominal density of boards were slightly different to each other. All the panels (Date palm and reference panel) made with $9 \mathrm{~mm}$ of thickness before sanding have reached the acceptable density which about $\pm 0.008 \%$ of the variations and all of them are exceeded the acceptable range according to the EN 323 .

\subsection{Vertical Density Profile}

The density of a board is seldom uniform throughout its thickness; variations constitute the so called "density profile (DP) or vertical density profile (VDP)," which should be nearly symmetrical and not skewed. An extreme variation of density between faces and core should be avoided, however, because it indicates an inferior board with low internal bond in the core (Thomas, 1987). Figure 3 shows the typical VDP example of the panels (M-shaped profile). The M-shaped formed might be explained due to the hot-pressing process, during the process, pressing stresses vertically applied to the mat from the press are always the same through the thickness. Usually, face density is higher than core density, which produces an M-shaped VDP. In addition vertical density profile (VDP) featured two types of shapes those are flat-shaped and classic M-shaped. 


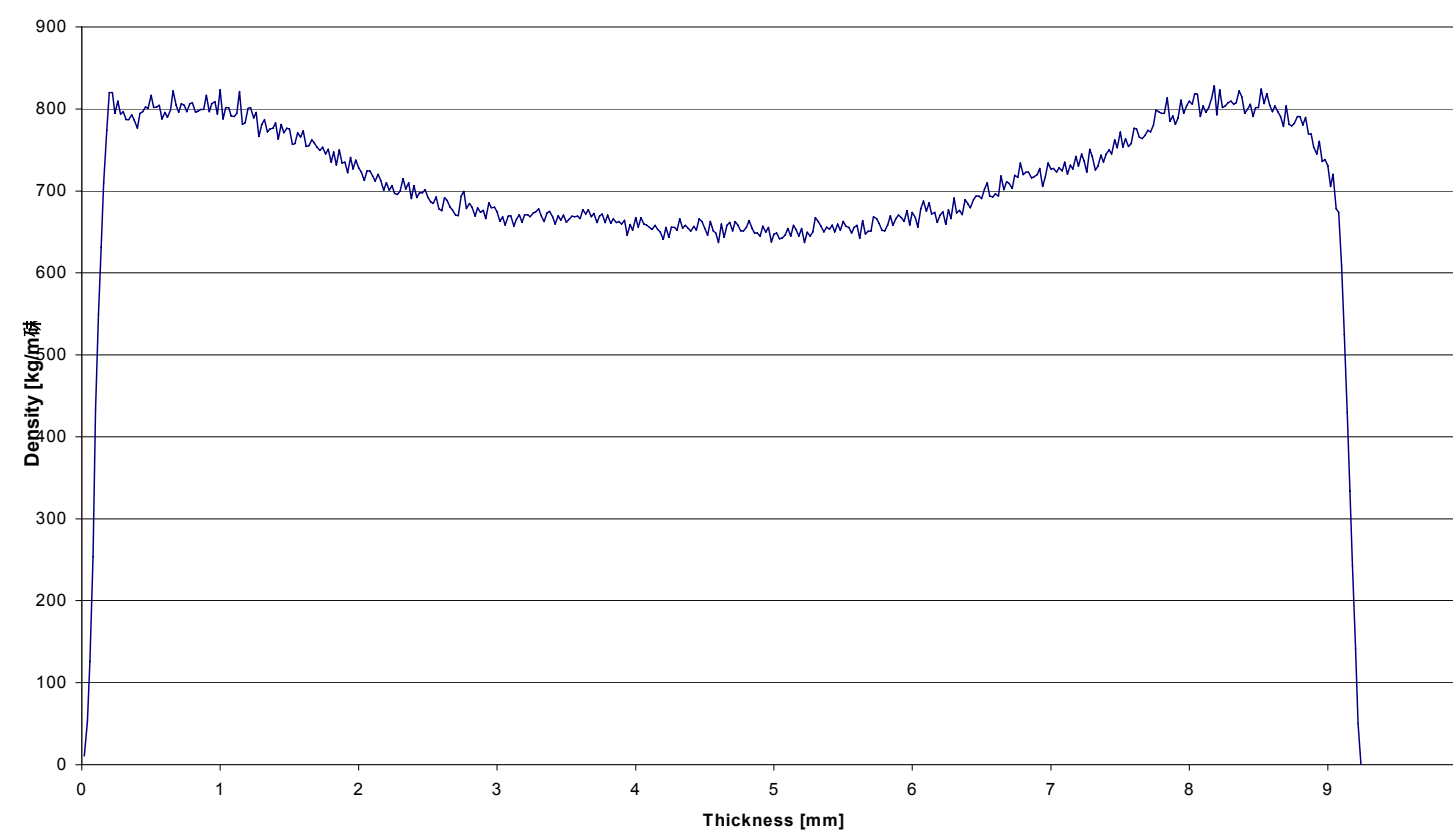

- Density mean: $746.69 \mathrm{~kg} / \mathrm{m}^{3}$

- Density max: $828.53 \mathrm{~kg} / \mathrm{m}^{3}$

- Density min: $637.09 \mathrm{~kg} / \mathrm{m}^{3}$

Figure 3. VDP of a MDF board with $9 \mathrm{~mm}$ nominal thickness before sanding (Having a classic M-Shaped)

Suchland and Woodson (1974); Winistorfer et al. (1996), and Ganev (2002) have studied that the VDP and its effect on performance directly result from the combined effects of many process parameters, including furnish characteristics (mat moisture and resin contents), pressing temperature, and pressing strategies. Different pressing strategies (different closing rates and steps) are commonly used to manipulate VDP according to the final MDF product application. Moreover, Wang et al. (2004) mentioned that closing the press slowly resulted in flatter density profiles, whereas closing the press more rapidly produced gradients that are more definitive, and a classic M-shaped profile. Finally, it can be concluded that MDF boards could be produced with desirable performances ranging from classic VDPs with dense faces and less dense cores.

\subsection{Formaldehyde Emission}

Natural wood has perforator values $<2 \mathrm{mg} / 100 \mathrm{~g}$ dry matter (Schafer \& Roffael, 2000) and the maximum allowable formaldehyde content from board is $\mathrm{g}<8 \mathrm{mg} / 100 \mathrm{~g}$ dry matter in class E1 (Table 4). Research continues on reducing fume emissions by adjusting resin formulations or adding scavengers (Roffael et al., 1975). Determination of formaldehyde emission behavior can be done by using desiccator, perforator, gas analysis, flask method and dynamic chamber methods. In this study perforator methods were used and the results are shown in Figure 4.

Table 4. Requirements for formaldehyde content (g) and formaldehyde emission (e) of MDF.

\begin{tabular}{ccc}
\hline & Formaldehyde content & Formaldehyde emission \\
class & $\mathrm{EN} 120$ & $\mathrm{EN} 317-1$ \\
& $\mathrm{mg} / 100 \mathrm{~g}$ MDF & $\mathrm{mg} / \mathrm{m}^{3}$ air \\
\hline E1 & $\mathrm{g}<8$ & $\mathrm{e}<0.124$ \\
E2 & $8<\mathrm{g}<30$ & $\mathrm{e}>0.124$ \\
\hline
\end{tabular}




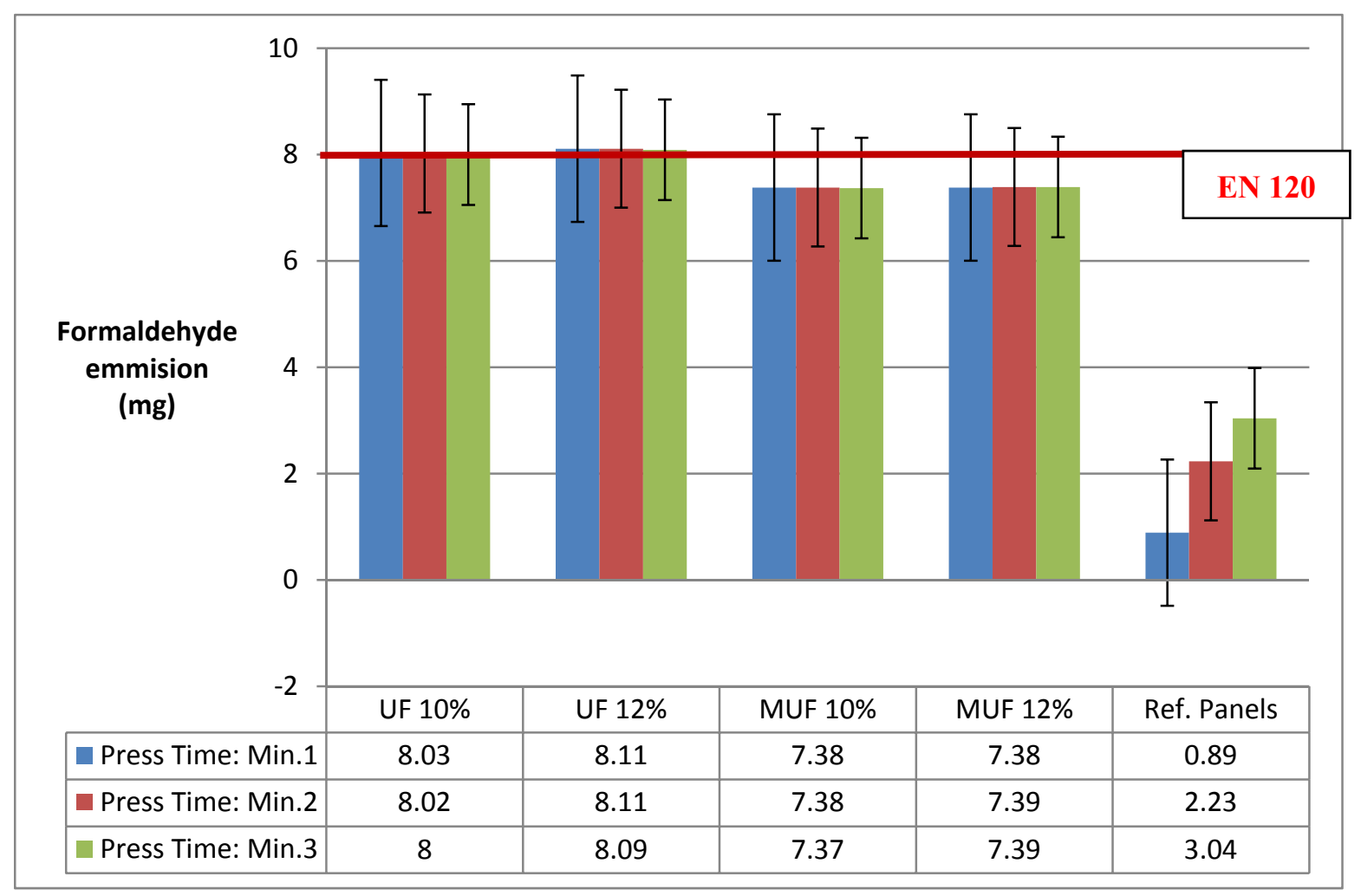

Figure 4. Effect of variable factories (resin content, resin type and pressing time) on formaldehyde emission of boards

Based on this study the formaldehyde emission of the made panels featured that all panels bonded with MUF resin meet the minimum requirement according to EN 120 and therefore belong to the E1 class (Table 4 and Figure 4). Moreover, using UF resin supposed to have higher formaldehyde release from the panels than those of the panels bonded with MUF resin. It was expected that by applying MUF as bonding agent would reduce the formaldehyde emission in comparison to the UF resin applied. Roffael (1982) mentioned that the hydrolysis of the resin is favored in high temperature, acidity, moisture, as well as air exchange rate. Therefore, the data obtained from the panels were highly fluctuated because it depends hardly on both factors external and internal. Panels which bonded with $12 \%$ UF achieved the highest perforator value about $8.11 \mathrm{mg} / 100 \mathrm{~g}$ and the lowest was $8.00 \mathrm{mg} / 100 \mathrm{~g}$. While, panels which bonded with $12 \%$ MUF resin contained around $7.39 \mathrm{mg} / 100 \mathrm{~g}$ and the lowest is presented in panel which bonded with $10 \%$ resin MUF (7.37 mg/100 g sample). This values, however, especially for MUF bonded panels are below the standard according to EN 120 in which the maximum formaldehyde content allowed is $8 \mathrm{mg}$ $\mathrm{HCHO} / 100 \mathrm{~g}$ dry sample. Whereas, the highest achieved perforator value for reference panels is around 3.04 $\mathrm{mg} / 100 \mathrm{~g}$ sample and the lowest is $0.89 \mathrm{mg} / 100 \mathrm{~g}$ sample. These values, however, are still below the standard and compared to the Date palm boards are satisfactory. It should be also added that by applying MUF as bonding agent would reduce the formaldehyde emission almost $9 \%$ in comparison to the UF resin applied. The achieved result in case of formaldehyde emission from the panels bonded with MUF resin quite similar to the Roffael et al., (2006) report. Also, in order to reduce formaldehyde emission, it is recommended to spray $0.5 \%$ urea on the fibers before mixing with resin particularly when UF resin is applied (Kharazipour, 2010). The results are further confirmed with the statistical analysis, show that the different resin type and resin content has a significant effect on formaldehyde emission value, where as there is no significant differences between pressing time at the different levels $(1,2$ and $3 \mathrm{~min})$. It might be due to the several factors which affecting formaldehyde emission rate from panels.

- Nature of raw material: Date palm is classified as a non wood material belonging to the Angiosperms-Monocotyledones and it has different characteristics compared to the real wood such as hard wood or soft wood.

- $\quad$ Press temperature and press time: Within panels hot pressed using the UF resin, panels pressed at the lower temperature, longer pressing time condition emit less formaldehyde. 
- Moisture content: wood is a hygroscopic material and has ability to exchange its moisture content with air. Formaldehyde emissions correlated well with the amount of water vapor collected for panels pressed with UF.

- Resin concentration: The higher the concentration of formaldehyde resin used in a panel, the higher its formaldehyde emission rate all other factors remained the same.

Finally, it can be concluded that the formaldehyde (HCHO) emission of the panels featured that almost all panels meet the minimum requirement according to EN 120 especially for the panel bonded with MUF resin.

\subsection{Physical Properties}

\subsubsection{Thickness Swelling}

The maximum thickness swelling recommended by the EN 317 standard for MDF is $15 \%$. As it is shown in figures 5 and 6 in the case of TS after $2 \mathrm{~h}$ immersion in water, all of the panels meet the minimum requirement according the EN 622-5 (1998) but, in the case of TS after $24 \mathrm{~h}$ immersion in water, none of the panels which bonded with UF resin meets the minimum requirement according to the EN standard (Figures 6). However, panels made which bonded with MUF resin obtained lower TS values compared to the others. Additionally, the relation between resin type and TS are varies which all panels particularly bonded with MUF performed positively correlated.

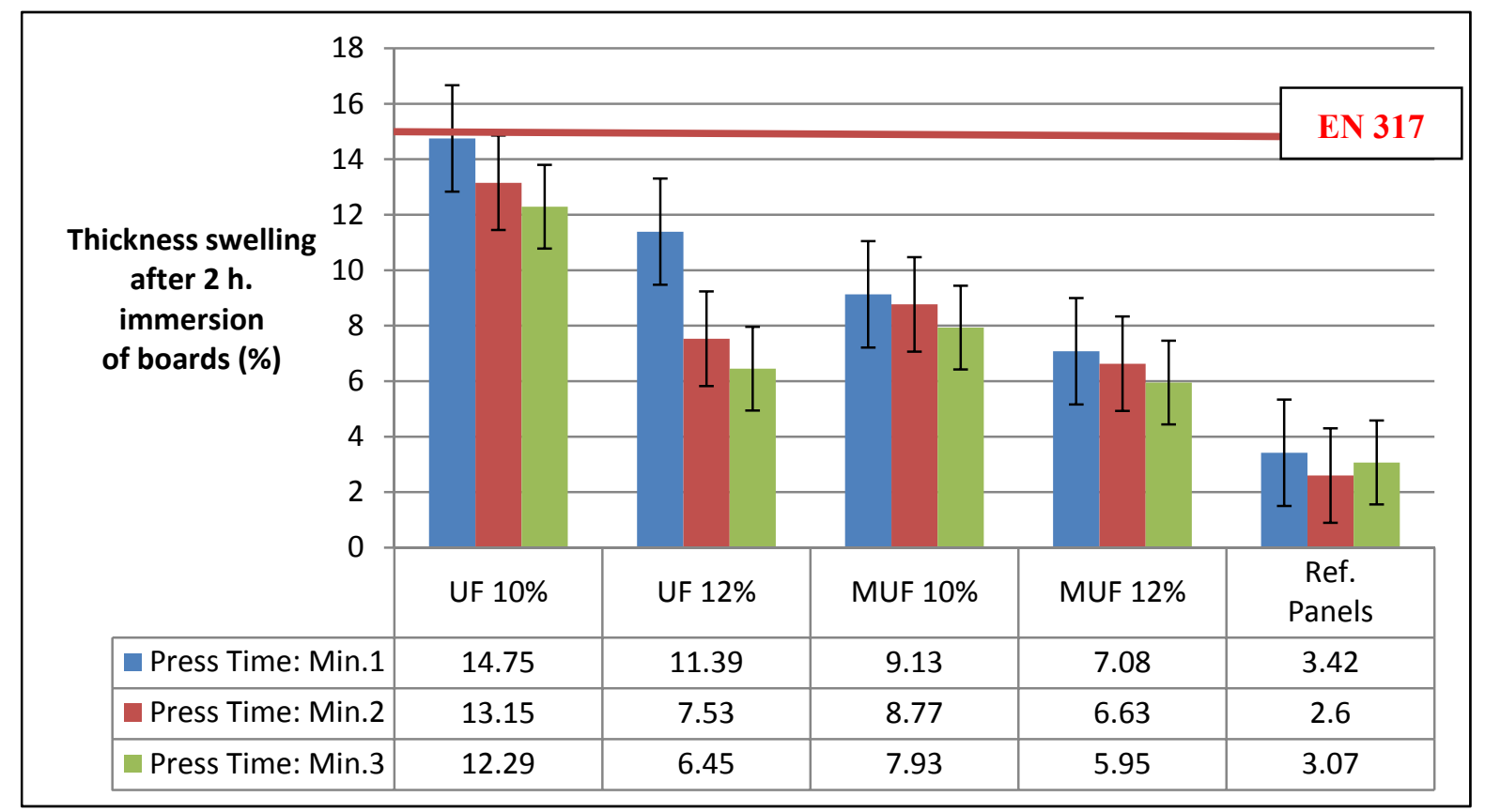

Figure 5. Effect of variable factories (resin content, resin type and pressing time) on thickness swelling after $2 \mathrm{~h}$. immersion of boards 


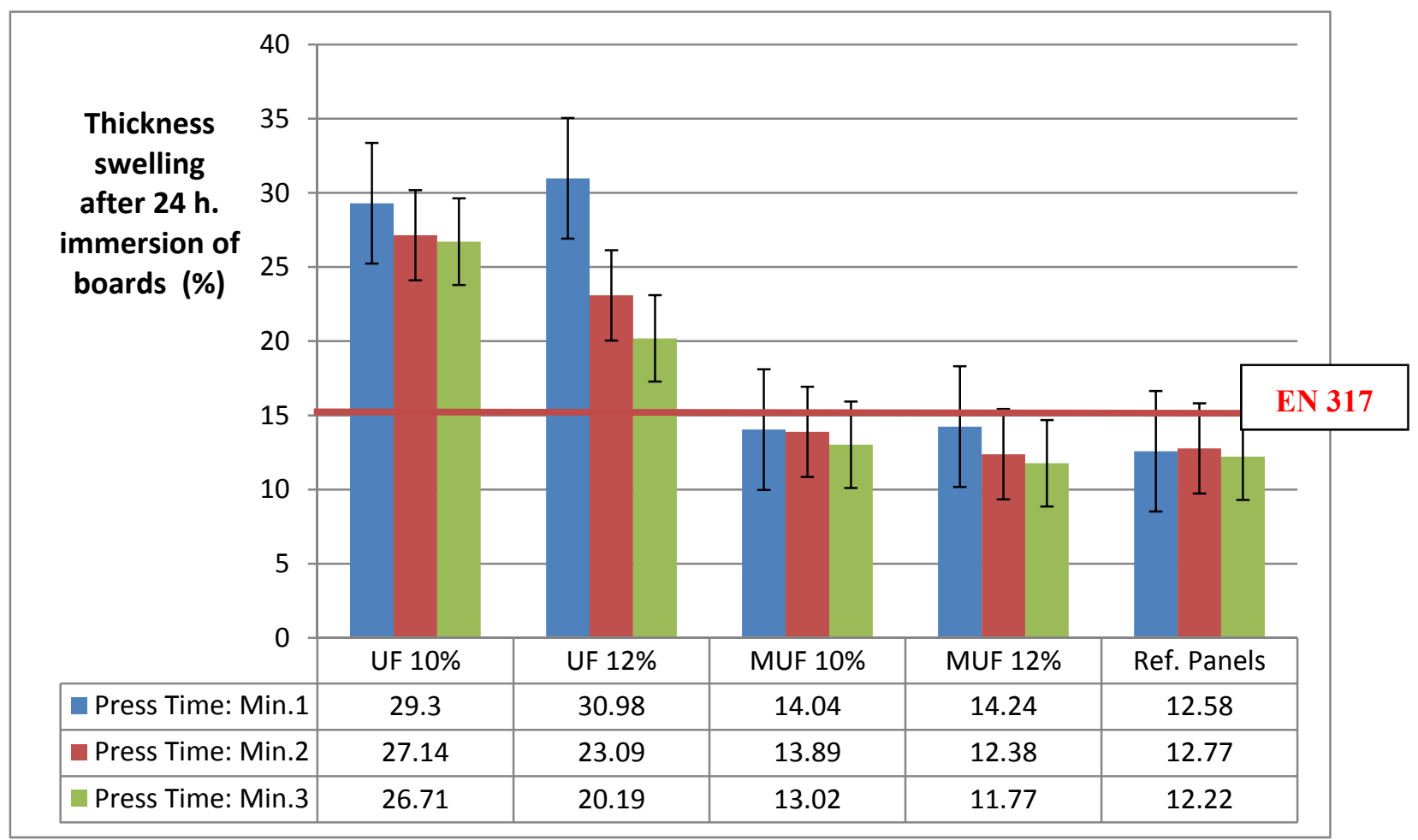

Figure 6 Effect of variable factories (resin content, resin type and pressing time) on thickness swelling after $24 \mathrm{~h}$. immersion of boards

The result demonstrations that the thickness swelling value of MDF bonded with UF resin are higher than that of the standard requirement. Several possible reasons might explain for this circumstance.

The tissue of the Date palm consists of fiber-like structural features known as vascular bundles and parenchyma cells. The distribution of cells shows a definite pattern, such as specific gravity, with in the trunk and the other part (branch), both horizontally and vertically. Furthermore, the outer part of branch has a far higher specific gravity than the inner part (Tomlinson, 1990). This variation could influence glue bonding, because the resin must be as strong as the high specific gravity zones and be able to penetrate them adequately without over-penetrating the low specific gravity zones. Furthermore, the wax layer of the epidermis (Tomlinson, 1990) may have affected the bond strength of the board. This may affect the bond strength of the Date palm board. Additionally, it has been previously known that the agricultural residues have extremely high buffer capacity when compared to normal wood. This property makes these materials unsuitable for use with some of the commercial resin used for wood based boards. Thence, thickness swelling is the limiting property (Hague et al., 1998; Sauter, 1996). Also it can be mentioned that because of high amount of Compression ratio, Bulky raw material, low percentage of resin cannot cover of whole surfaces of fiber so it was achieved high percentage of thickness swelling when compared with more resin content. On the other hand, increasing the resin content improved its water resistance and reduced its TS. The water resistance of all boards was also affected by the variation of the resin type.

From Figure 6 it can be seen that MUF bonded board shows less thickness change than those of other boards. Moreover, board made with higher resin content results in improved dimensional stability similar to the findings of previous works (Lee et al., 1996; Nugroho \& Ando, 2000). These results are further confirmed with the statistical analysis that the different resin type and resin content have a significant effect on TS value. Notable, the UF bonded board shows a significant higher TS value than those of others. It can be explained as a result of the higher hydrolysis sensitivity of the UF resin. The lack of resistance to high moisture content is attributed to the presence of hydrolysable group between carbon of the methylene linkage and nitrogen of urea (Pizzi, 1994). From achieved results it can be seen clearly the thickness swelling (TS) declined with increased resin content and thickness swelling of all boards was also affected by the variation of the resin type.

Table 5 shows main physical and mechanical properties of some non-wood fiber based MDF and based on achieved results Date palm MDF has high thickness swelling value like those panels which made of Cotton straw, Oil palm, Reed, Bamboo. Thus it can be said Date palm MDF has high thickness swelling value like panels which 
made of oil palm (Table 5). It seems both of them (Oil palm and date palm) have same circumstance in aspect of physical property and more study should be done to solve this problem. Thickness swelling value of the reference panels are between 2.42 to $3.07 \%$ for $2 \mathrm{~h}$ soaked in water. While after $24 \mathrm{~h}$., the TS rate increase to 12.22 to $12.58 \%$. However based on the achieved results, it can be said after $24 \mathrm{~h}$., measurement all of the reference panels were fulfill this requirement where the minimum values are $15 \%$ for the panels having the thickness of $9 \mathrm{~mm}$.

Table 5. Main physical and mechanical properties of non-wood fiber based MDF

\begin{tabular}{ccccccc}
\hline Properties & \multicolumn{2}{c}{ Cotton straw } & Bamboo & Reed & Bagasse & Oil palm* \\
\hline Board thickness (mm) & 18 & 9 & 9 & 9 & 9 & 6.4 \\
MOR & $30-40$ & $32-36$ & 25 & $26-30$ & $30-35$ & $37-22.8$ \\
$(\mathrm{MPa})$ & & & & & & \\
IB & $0.5-0.6$ & $0.60-0.65$ & 0.50 & $0.45-0.55$ & $0.60-0.65$ & $0.8-0.7$ \\
$(\mathrm{MPa})$ & $14-17$ & $22-26$ & 20 & $16-20$ & 12 & $58-78$ \\
Water Absorption (\%) & $6-8$ & $6-10$ & 9 & $7-8$ & $4-6$ & $22-40$ \\
$\begin{array}{c}\text { Thickness Swelling (\%) } \\
\text { Specific gravity } \\
\left(\mathrm{g} / \mathrm{cm}^{3}\right)\end{array}$ & $0.65-0.69$ & $0.70-0.75$ & $0.70-0.75$ & $0.72-0.76$ & 0.70 & $0.1041-0.1057$ \\
\hline
\end{tabular}

Source: FAOSTAT and Ridzuan* et al. (2002).

\subsubsection{Water Absorption}

Investigation of WA showed that the panels as mentioned to the TS values featured the similar effects to the water absorption (WA), even though there are no standard are available at the moment, these panels absorbed more water compared to the others. But, the relationships between the increases of the resin content and pressing time are positively correlated. Soaking in water for $2 \mathrm{~h}$ no large differences in WA values were observed (Figure 7), but after $24 \mathrm{~h}$ soaking in water an effect can be seen very clearly (Figure 8).

However, panels which bonded with MUF resin obtained lower WA values compared to the others. Additionally, the relation between resin type and WA are varies which all panels particularly bonded with MUF performed positively correlated. WA value of the reference panels are between 9.34 to $17.15 \%$ for $2 \mathrm{~h}$ soaked in water. While after $24 \mathrm{~h}$., the TS rate increase to 18.12 to $46.39 \%$. However based on the achieved results, it can be said after $24 \mathrm{~h}$., measurement all of the reference panels have more or less same value as MUF boned panel. Based on achieved results Date palm MDF which bonded with 10\% UF resin has high WA value like panels which made of Oil palm (Table 5). It seems both of them (Oil palm and date palm) have same circumstance in aspect of physical property and more study should be done to solve this problem. 


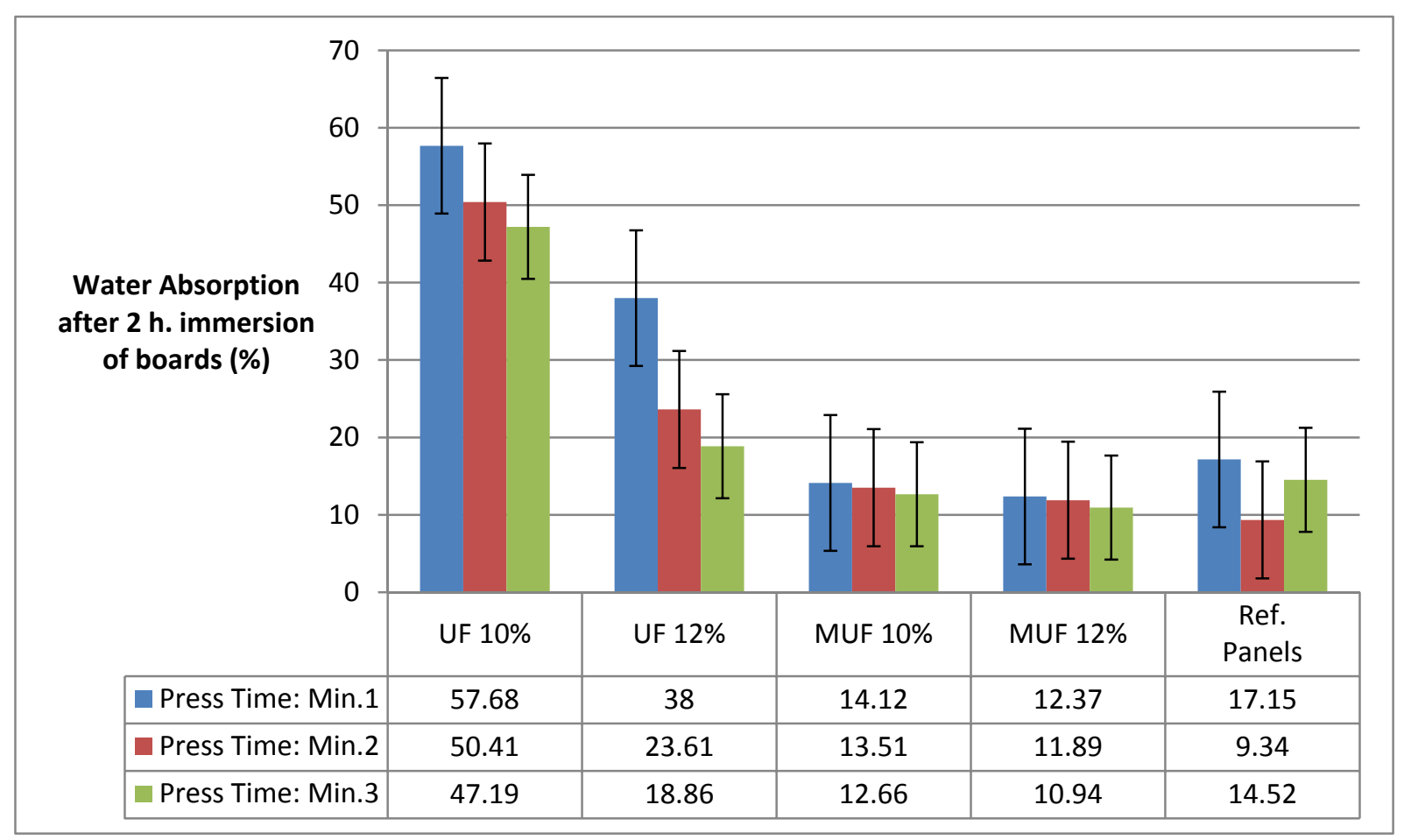

Figure 7. Effect of variable factories (resin content, resin type and pressing time) on water absorption after $2 \mathrm{~h}$. immersion of boards

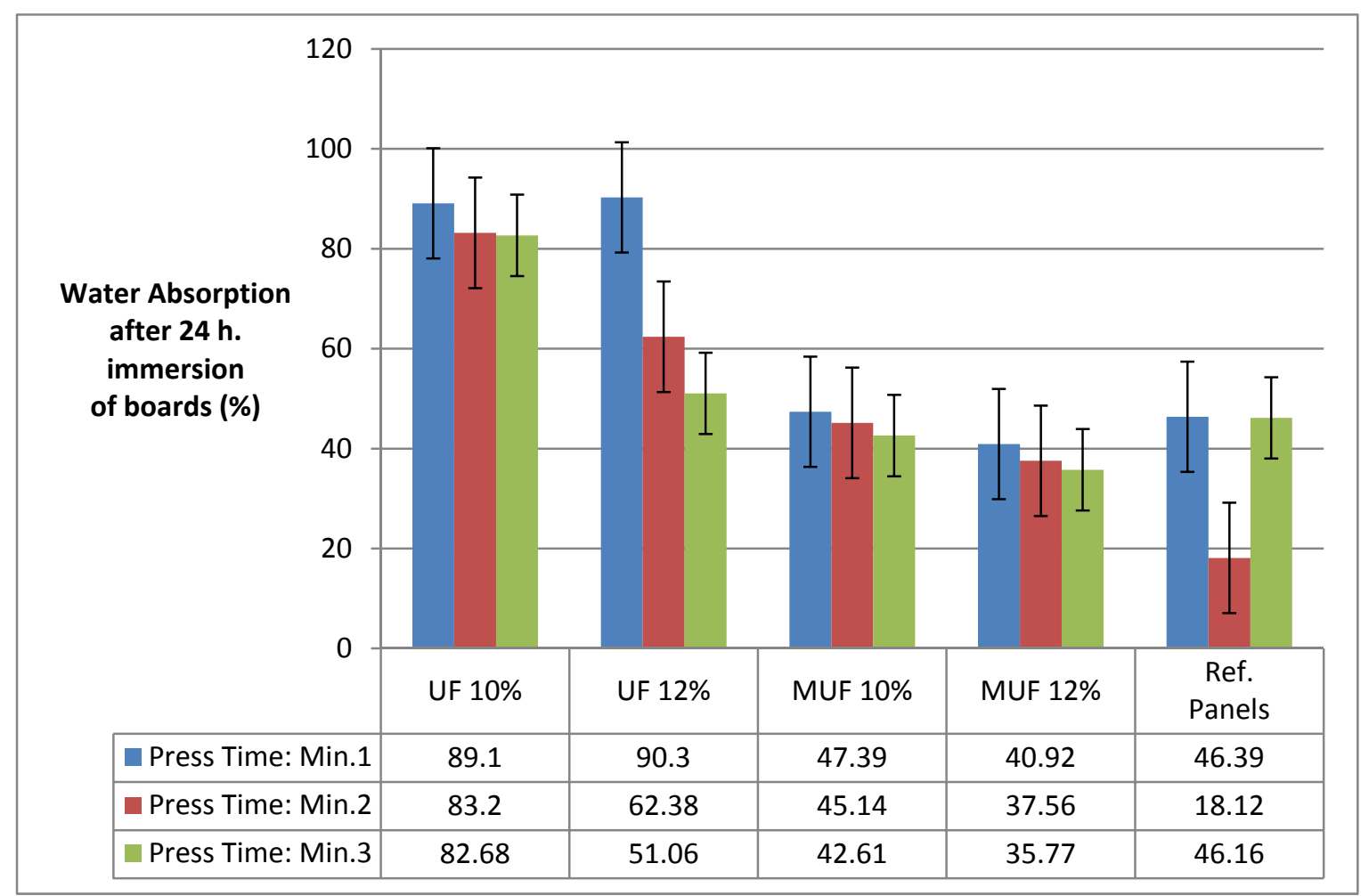

Figure 8. Effect of variable factories (resin content, resin type and pressing time) on water absorption after $24 \mathrm{~h}$. immersion of boards 
TS and WA of boards like the other non-wood fiberboards showed high water swelling levels (Figures. 5- 8). Hemi-cellulose is a branched, non-crystalline polymer which has the ability to absorb water and swell (Berthold et al., 1996) and at the different wood polymers in the cell wall, the hemicelluloses swell the most and lignin the least (Lindström \& Westman, 1980). The WA of produced boards was estimated more than the expected level. The water-repelling properties improved at higher resin content. The lowest (better value) thickness swelling and water absorption properties were achieved with applying UMF resin. Making boards with MUF resin resulted in the lowest TS and WA values.

Normally, the water absorption is carried out by hydrogen bonds with the hydroxyl groups that are available in hemicelluloses, lignin and cellulose. The water occupying a space in polymers inflates the cell walls and the wood expands as water is absorbed until the cell walls are saturated (fiber saturation point). This phenomenon is reversible and wood shrinks when it loses moisture below to this point (Rowell, 1988; Rowell et al., 1993). Therefore, wood is defined as a hygroscopic material that swells by absorbing moisture and contracts while losing moisture below this point (Kollmann \& Côté, 1968). However, above the fiber saturation point, moisture exists in the form of open water that does not contribute to the swelling of the wood. Raw materials influence the WA value by mean that the different fiber characteristic leads to different absorbing power for the water penetrates into cavities of the cell. Therefore, Kollmann and Côté (1968) noted that the larger the pore volume of the cell, the higher the water would be absorbed.

\subsection{Mechanical Properties}

Main mechanical properties, are static bending (modulus of rupture and elasticity), and internal bond (transverse tension) (Bodig \& Jayne, 1982). Mechanical properties discussed in this part have been obtained from tested of samples. Many of the mechanical properties of boards tabulated in this part were derived from extensive sampling and analysis procedures. Firstly experimental results were analyzed. Secondly experimental results were compared with the minimum property requirements for MDF which are specified by the EU Standard for MDF.

\subsubsection{Bending Strength (MOR)}

The minimum MOR required by the EN 310 standard for MDF is $22 \mathrm{~N} / \mathrm{mm}^{2}$. The bending strength (MOR) values which achieved in this study are in the range of $19.22-30.52 \mathrm{~N} / \mathrm{mm}^{2}$. The analysis of variance testing conducted on the effect of the three factors and their interaction, confirms here that the resin type, resin content and pressing time significantly influence the MOR.

From Figure 9, it can be seen that the MOR value of UF-bonded board is highest, while those of MUF-bonded boards are lowest. One explanation may lie in the high bonding strength of the cross linked fiber network of UF resin. As well, the resin content contributes to improve board strength. In basic knowledge, it can be described the relationship between resin content and product strength that with the increasing of resin content, the product strength will improve by the increase of the intimate contact area between adjacent fibers in the board. These results are also in agreement with the result of Barnes (2000) who shows that with higher resin content of composite board, the physical and mechanical properties of board increase.

Comparing the mean values of all boards, the MOR value of UF-bonded board in the same press time is highest, as shown in Figure 9, while those of MUF -bonded boards are less. The higher MOR of UF bonded board is due to the high bonding strength of the cross linked fibers network. This is in agreement with the result of Nikvash et al. (2012). 


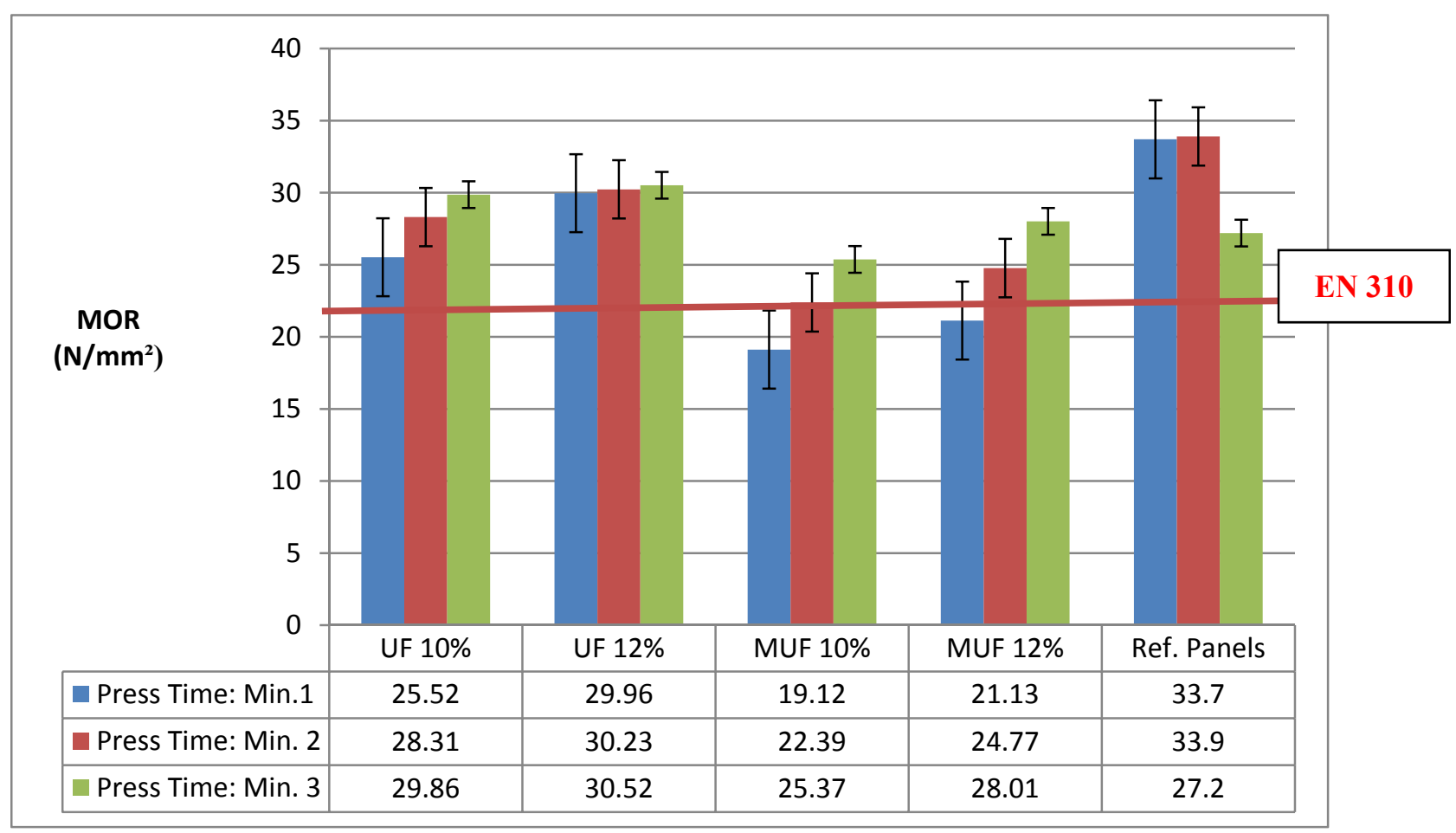

Figure 9. Effect of variable factories (resin content, resin type and pressing time) on MOR of boards

Notable, 10\% MUF-bonded board shows the lowest value of MOR. This might be due to its inadequate time for polymerization of resin (around $19.12 \mathrm{~N} / \mathrm{mm}^{2}$ as presented in Figure 9). MDF made showed the highest MOR $\left(30.52 \mathrm{~N} / \mathrm{mm}^{2}\right)$ which is higher than the values of 23.4, 12.2 and $13.0 \mathrm{~N} / \mathrm{mm}^{2}$ obtained by Faraji (1998), Habibi et al.,(2002) and Lee et al., (2004), respectively. Also based on achieved results Date palm MDF has more or less MOR value like those panels which made of Cotton straw, Oil palm, Reed, Bamboo (Table 5). In addition comparing the mean values of all boards, the MOR value of reference board in the same press time and resin content is highest, as shown in Figure 9, the MOR value of all reference panels are between $27.2-33.9 \mathrm{~N} / \mathrm{mm}^{2}$.

Regarding to the bending strength (MOR) of the panels, all of them except board which bonded with 1 min. pressing time and consumption $10 \%$ MUF resin meet the minimum requirement according to the EN 622-5 (1998). However, the Date palm panels bonded with $12 \%$ UF resin and having performed higher values among the others. In fact, the increases of the resin content of the panels have positive correlation for bending strength.

\subsubsection{Modulus of Elasticity in Bending (MOE)}

The minimum MOE required by the EN 310 standard for MDF is $2500 \mathrm{~N} / \mathrm{mm}^{3}$. The bending stiffness of boards is illustrated in Figure 10 and the achieved values for Date palm boards are in the range of 1520 to $2980 \mathrm{~N} / \mathrm{mm}^{2}$. The analysis of variance testing conducted on the effect of the three factors and their interaction, confirms here that the resin type, resin content and pressing time significantly influence on MOE. From Figure 10 the result suggests that MOE of boards are mainly influenced by the resin type. The maximum value is $2980 \mathrm{~N} / \mathrm{mm}^{2}$ for board which bonded with UF at $12 \%$ resin content, while the minimum value is $1520 \mathrm{~N} / \mathrm{mm}^{2}$ for MUF at $10 \%$ resin content. It is possible to distinguish the difference between different bonded boards. Also the value of UF bonded board are almost 50\% higher than MUF bonded board at the same level of resin content. Notable, 10\% MUF-bonded board with 1 min. pressing time shows the lowest value of MOE (around $1520 \mathrm{~N} / \mathrm{mm}^{2}$ ). This might be due to its inadequate resin and time for polymerization of resin. As presented in Figure 10, MDF made showed the highest $\operatorname{MOE}\left(2980 \mathrm{~N} / \mathrm{mm}^{2}\right)$ which is higher than the values of 1,936, 1,370 and 1,578 MPa obtained by Faraji (1998); Habibi et al. (2002); and Lee et al. (2004) respectively. 


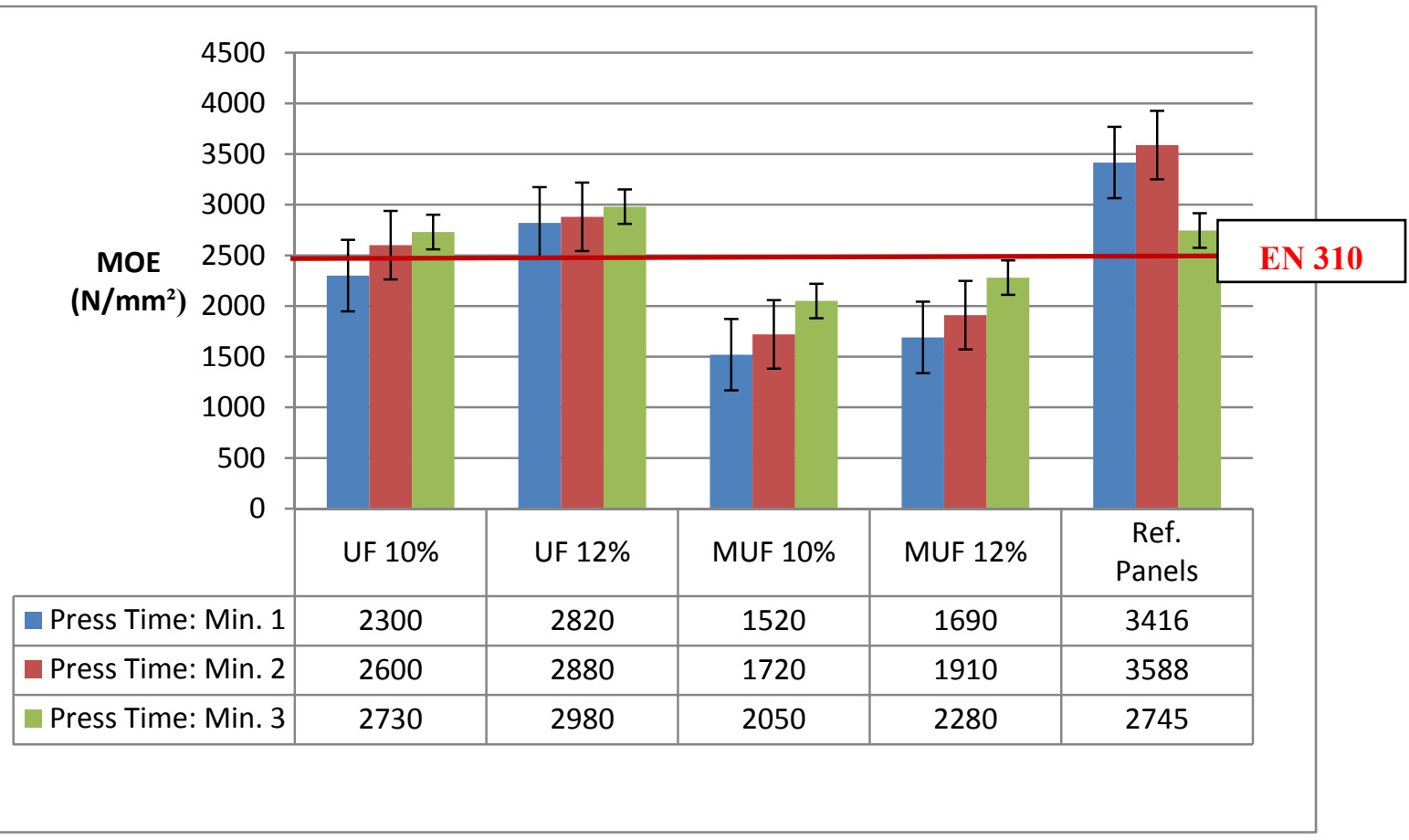

Figure 10. Effect of variable factories (resin content, resin type and pressing time) on MOE of boards

Relationship between two parameters (resin type and content) and MOE value of the boards is illustrated in Figure 10. The maximum value of MOE is $2980 \mathrm{MPa}$ for UF at $12 \%$ resin content, while the minimum value is $1520 \mathrm{MPa}$ for MUF at $10 \%$ resin content. UF and MUF bonded boards do not show quite similar MOE value and UF resin bonded boards have approximately $67-69 \%$ higher than MUF board at the same level of resin content. Moreover, the MOE value increases with increasing resin content. In addition comparing the mean values of all boards, the MOE value of reference board in the same press time and resin content is highest, as shown in Figure 10, the MOE value of all reference panels are between 2745 to $3588 \mathrm{~N} / \mathrm{mm}^{2}$ (Figure 10).

To address the known relationship between resin content and product bending stiffness, increasing the resin content, the product bending stiffness will increase too. As the resin is increased, there will be an increase of the intimate contact area between adjacent Date palm fibers in the board. The current finding shows that increasing the resin content from $10 \%$ to $12 \%$ improves the MOE rapidly particularly boards which bonded with MUF resin. Additionally, the resin type is found to be the major factor contributing to the improvement of stiffness of board.

\subsubsection{Internal Bond Strength (IB)}

The tensile strength perpendicular to surface is defined in accordance with EN 319 and determines the normal force required to pull a panel apart in the thickness direction. According to EN 622-5: 1998, the minimal requirement of internal bond for MDF is $0.6 \mathrm{~N} / \mathrm{mm}^{3}$. The Inter bond of boards is illustrated in Figure 11 and the achieved values are in the range of 0.61 to $0.92 \mathrm{~N} / \mathrm{mm}^{2}$. Furthermore, MDF made had highest internal bond (more than $0.61 \mathrm{~N} / \mathrm{mm}^{2}$ ), which was higher than 0.38, 0.13 and $0.31 \mathrm{MPa}$ for MDF made by Lee et al., 2004; Habibi et al., 2002; and Faraji, 1998 respectively. The internal bond strength (IB) of Date palm MDF made with different resin types and content is shown from Figure 11 the minimum value is $0.61 \mathrm{~N} / \mathrm{mm}^{2}$ for the board made with $10 \%$ MUF resin content, while the maximum value is $0.92 \mathrm{~N} / \mathrm{mm}^{2}$ for the board made with $12 \%$ UF resin content. The analysis of variance result conducted on the effect of two factors and their interaction shows that the resin type and pressing time significantly influences the internal bond.

The result of the analysis of variance conducted on the effect of the different factors and their interaction shows that the resin type and resin content does not significantly influence the internal bond. The internal bond values should be discussed in reference to the resin content because it strongly depends on the amount of resin applied. Then, the value consequently increases with the increase of the resin content. For UF resin, internal bond is greater than the other type (MUF) because the high strength of covalent bonds between fibers in the board. Based on achieved results Date palm MDF has more IB value those panels which made of Cotton straw, Oil palm, Reed, 
Bamboo (Table 5). In addition comparing the mean values of all boards, the IB value of reference board in the same press time and resin content is more or less low particularly for the made board with 1 min. press time, as shown in Figure 11, the IB value of all reference panels are between 0.57 to $0.67 \mathrm{~N} / \mathrm{mm}^{2}$ (Figure 11). Internal bond strength (IB) of the panels showed that all panels meets the minimum required values according to the EN 622-5 (1998) Therefore, pressing time, resin content as well as resin types have a big influence on IB strength.

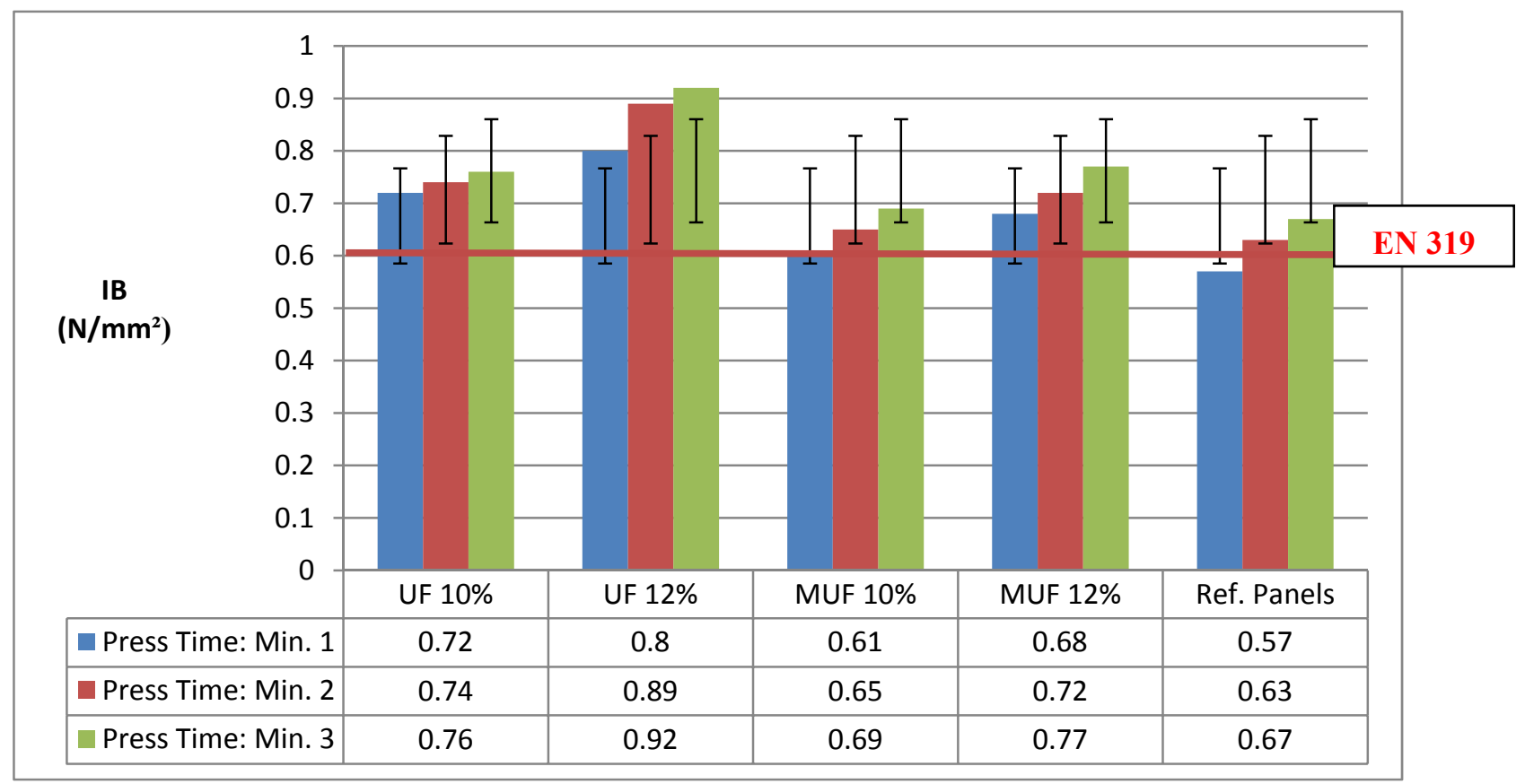

Figure 11. Effect of variable factories (resin content, resin type and pressing time) on IB of boards

In the end it can be concluded that based on the results of this study, using Date Palm Pruning fiber with $750 \mathrm{Kg} / \mathrm{m}^{3}$ of the density adjusted to the $9 \mathrm{~mm}$ of the thickness and glued with UF (Urea formaldehyde) resin gave good performance of each properties except thickness swelling (TS) and water absorption (WA) which the problem can be solved if MUF resin is used. Also based on ASTM standard (ASTM D 1037-96a), in aspect of mechanical property all of boards can be classified in grade 130. However, it has been concluded that Date palm fiberboards can be manufactured by conventional dry processes. Therefore, Date palm could be proposed as an alternative material for the manufacture of MDF.

\section{Conclusions}

The results of this study show clearly that boards made of Date Palm pruning residues fibers feature better properties than the MDF property requirements which is recommended by EN standards particularly inspect of mechanical properties. Therefore, Date palm could be proposed as an alternative material for the manufacture of MDF. The results from this experiment indicate that pilot plan MDF panels made from can be fabricated with panel properties that exceed levels specified in the appropriate existing standards. Further experimentation with other variable factors must be conducted to confirm our findings with Date palm and allow comparisons. These research results are promising and indicate that date palm pruning residues be successfully used for the production of MDF, a value-added panel product. Date palm waste may create problems of supply because, though they are produced in large quantities, they are quite dispersed and transport costs for this bulky raw material may become more or less a limiting factor so further study is recommended for its economic surveys. Additionally, full production trials must be conducted to confirm our pilot-scale results.

\section{Acknowledgements}

The authors gratefully acknowledge the productive collaboration with the Georg-August-Universität Göttingen (University of Göttingen), Germany and Research Institute of Forests and Rangelands, Iran. 


\section{References}

ASTM D1037. (1999). Standard Test Methods for Evaluating Properties of Wood-Base Fiber and Particle Panel Materials (pp. 699-706). ASTM D1037-99, ASTM, West Conshohocken.

Barnes, D. (2000). An integrated model of the effect of processing parameters on the strength properties of oriented strand wood products. Forest Product Journal, 50(11/12), 33-42.

Berthold, J., Rinaudo, M., \& Salmén, L. (1996). Association of water to polar groups; estimation by an adsorption model for ligno-cellulosic materials. Colloids Surf. Part A, 112, 119-131.

Bodig, J., \& Jayne, B. A. (1982). Mechanics of Wood and Wood Composites. New York: Van Nostrand Reinhold.

Djerbi, M. (1995). Précis de Phoeniciculture. FAO. 192 pp

Dube, H., \&Kehr, E. M. (1995). Use of waste paper in MDF manufacture - influence of the proportion of waste paper. Holz-als-Roh-und-Werkstoff., 53(1), 20. http://dx.doi.org/10.1007/BF02716378

EN 120-1. (1994). Determination of formaldehyde content in fiberboard by using perforator method. Brussels-Belgium: European Committee for Standardization.

EN 317. (1993). Chipboard and fiberboard - Determination of thickness increase by swelling after immersion in water.

EN 622-5. (2006). Fiberboards - Specifications - Part 5: Requirements for dry process boards (MDF).

FAO. (2002). Date Palm cultivation. Corporate Document Repository. Rome: Food and Agricultural Organization of the United Nations.

FAOSTAT. (2009). Reports.

Faraji, H. (1998). Investigation on the medium density fiberboard properties made out of the Baggasse. Faculty of Nour natural resources. M.Sc. dissertation.

Ganev, S. (2002). Modeling of the hygromechanical warping of medium density fiberboard. Ph.D. Thesis, Forestry Faculty, University of Laval, Canada, p 180.

Habibi, M. R., Hossienzadeh, A. R., Mahdavi, S., Hossienkhani, H., \& Sepedehdam, J. (2002). Effect of Bagasse Fibers on Medium Density Fiber Board Properties. Iranian Res. J. Wood and Paper Sci., (16), 29-55.

Hague, J., McClauchlin, A., \& Quinney, R. (1998). Agri-material for panel products: a technical assessment of their viability. In 32nd International Particleboard/Composite Materials Symposium Proceedings (pp. 151-159). Pullman, Washington, USA.

Hosseinkhani, H. (2013). Studies on Date Palm (Phoenix dactylifera L) Pruning Residues and its suitability for MDF Production. Sierke-Verlag, Auflage, Dezember 2013 Göttingen, Germany.

Hosseinkhani, H., Kargarfard, A., \& Golbabaei, F. (2000). Utilization of Bagasse and logging residues of Eucalyptus in Particleboard Production. Research Institute of Forests and Rangelands (RIFR).

Hosseinkhani, H., Kargarfard, A., \& Mahdavi, M. (2008). Utilization of agricultural residues potential as an alternative raw-material for wood and paper industries in Iran. Research Institute of Forests and Rangelands (RIFR).

Kargarfard, A., Latibari, A. J., \& Golbabaei, F. (2009). Kiwi pruning in particleboard production. Journal of Iranian wood science and wood industries research. Research Institute of Forests and Rangelands (RIFR). Tehran, Iran.

Kargarfard, A., Latibari, A. J., \& Golbabaei, F. (2009). Sunflower stalks. Journal of Iranian wood science and wood industries research. Research Institute of Forests and Rangelands (RIFR). Tehran, Iran.

Kharazipour, A. (2010). Personal conversation. Büsgen-Institut. Georg-August-Universität Göttingen, Germany.

Kollmann, F. F. P., \& Côté-Jr. W. A. (1968). Principles of wood science and technology. I solid wood. Springer-Verlag. Berlin. Heidelberg. 502 p.

Latibari, A., Hosseinzadeh, A., Kargarfard, A., \& Noorbakhsh, A. (1996). Investigation on production of Particleboard from Date palm residues. Iranian journal of wood and paper science, 1, 49-108.

Lee, S., Shupe, T. F., \& Chung, Y. H. (2004).Utilisation of Chinese Tallow Tree and Bagasse for Medium Density Fiberboard. Forest Product J., 54(12), 71-76. 
Lindström, T., \& Westman, L. (1980). The colloidal behavior of Kraft lignin. III. Swelling behavior and mechanical properties of Kraft lignin gels. Colloid Polym. Sci., 258, 390-397. http://dx.doi.org/10.1007/ BF01480830

Myers, G. C. (1983). Relationship of fiber preparation and characteristics to performance of medium-density hardboards. Forest-Products-Journal., 10, 43-51.

Nikvash, N., Kraft, R., Kharazipour, A., \& Euring, M. (2012). Comparative properties of bagasse, canola and hemp particle boards. Eur. J. Wood Prod., 68(3), 323. http://dx.doi.org/10.1007/s00107-010-0465-3

Nugroho, N., \& Ando, N. (2000). Development of structural composite products made from bamboo I: fundamental properties of bamboo zephyr board. $J$ Wood Science, 46, 68-74. http://dx.doi.org/10.1007/ BF00779556

Pizzi, A. (1994). Advanced wood adhesives technology. Marcel Dekker, Inc, New York. 289 p.

Ramli, R., Shaler, S., \& Jamaludin, M. A. (2002). Properties of Medium Density Ties of Medium Density Fibreboard from Oil Palm Empty Fruit Bunch Fibre. Journal of Oil Palm Research, 14(2), 34-40.

Roffael, E. (1982). Die Formaldehydabgabe von Spanplatten und anderer Werkstoffe. DRW-Verlag Stuttgard. http://dx.doi.org/10.1007/s00107-006-0141-9

Roffael, E. Dix, B., \& Schneider, T. (2007). Influence of Pulping process on the emission of formaldehyde and volatile organic acids from pulps and meduim density fiberboards (MDF). Holz Roh-Werkst, 65, 145-148. http://dx.doi.org/10.1515/hfsg.1992.46.2.163

Roffael, E., \& Dix, K. (1992). MDF from young poplar (Populus trichocarpa) of different properties. Holzforschung, 46(2), 163-170.

Roffael, E., Rauch, W., \& Bismarck, C. V. (1975). Formaldehydabgabe und Festigkeitsaus-bildung bei der Verleimung von Eichenspänen mit HF-Harz. Holz Roh-und Werkstoff, 32, 271-275. http://dx.doi.org/10.1007/BF02614465

Rowell, R. M. (1988). Can the cell wall be stabilized? In O. Dans Suchsland (Ed.), Wood Science Seminar. Stabilization of the Cell Wall (pp. 53-63). East Lansing, Mich.: Michigan State University.

Rowell, R. M., Cleary, B. A., Rowell, J. S., Clemons, C., \& Young, R. A. (1993). Results of chemical modification of lingo cellulosic fibers for use in composites. M. P. Dans Wolcot, (Ed.), Forest Wood Fiber/ Polymer Composites. Product Society, 121-134.

Sauter, S. L. (1996). Developing composites from wheat straw. In 30th International particleboard/Composite Materials Symposium Proceedings (pp. 197-214). Pullman, Washington, USA.

Schafer, M., \& Roffael, E. (2000). On the formaldehyde release from wood. Holz Roh-Werst, 58(4), 259-264. http://dx.doi.org/10.1007/s001070050422

Suchsland, O., \& Woodson, G. (1974). Effect of press cycle variables on density gradient of medium density fiberboard. In proceeding 8th particleboard symp (pp. 375-396).

Thomas, P. T. (1987). Using Density Profile meter for Quality and Consistency Measurements in MDF Manufacturing. Canada Alberta, Forest Resources Development Agreement.

Tomlinson, P. B. (1990). The Structural Biology of Palms. New York: Oxford University press.

Wang, S., Winistorfer, P. M., \& Young, T. M. (2004). Fundamentals of vertical density profile formation in wood composites. Part III. MDF density formation during hot-pressing. Wood and Fiber Sci., 36(1), 17-25.

Wang, T. Y. (1991). A preliminary study on the MDF made from bamboos. Wood Industry Beijing, 5(1), 6-10.

Winistorfer, P. M., Young, T. M., \& Walker, E. (1996). Modeling and comparing vertical density profiles. Wood Fiber Sci., 28(1), 133-141.

\section{Copyrights}

Copyright for this article is retained by the author(s), with first publication rights granted to the journal.

This is an open-access article distributed under the terms and conditions of the Creative Commons Attribution license (http://creativecommons.org/licenses/by/3.0/). 